\title{
DISCURSOS DA CIDADANIA E EDUCAC̣ÃO EM CIÊNCIAS NOS LIVROS DIDÁTICOS
}

RESUMO: Neste trabalho são apresentados os resultados de uma investigação que buscou identificar os sentidos da cidadania em livros didáticos de Ciências destinados às séries finais do Ensino Fundamental. Para isso, inicialmente apresentamos alguns modelos que articulam ciência e cidadania em diálogo com algumas noções da filosofia política contemporânea e que tomamos como base para as análises que realizamos. Nas análises dos livros selecionados, operamos com a categoria representação discursiva, utilizada nos referenciais da análise crítica do discurso. Nossos resultados apontam para a coexistência de diferentes discursos sobre cidadania nos textos, o que reflete o caráter de tensão permanente entre os recursos ideológicos e materiais mais estáveis e as propostas de mudança na educação em ciências.

Palavras-chave: Livros didáticos. Cidadania. Discursos.

\section{CITIZENSHIP DISCURSES AND SCIENCE EDUCATION IN SCHOOL TEXTBOOKS}

ABSTRACT: This paper presents the results of an investigation that aimed to identify the meanings of citizenship in school science textbooks. For that, some models that articulate science and citizenship in dialogue with notions from contemporary political philosophy were employed as a reference to our analysis. Our results point to a coexistence of different citizenship discourses in the texts, reflecting the tensions between established ideological and material resources and the transformation proposals in science education.

Keywords: Science textbooks. Citizenship. Discourses. 


\section{INTRODUCุ̃̃O}

Atualmente, muitos defendem que uma cidadania instruída e informada reclama maior responsabilização para decisões sobre ciência e tecnologia, e isso gera uma série de demandas - e debates - no campo da educação em ciências. De fato, nas últimas décadas, as finalidades da educação científica vêm sofrendo modificações em suas esferas curriculares e pedagógicas em todo o mundo. Os objetivos fundadores da educação em ciências, voltados para a formação de futuros cientistas, vêm sendo problematizados e ampliados em função de uma série de fatores, que vão desde a democratização do acesso à educação básica aos impactos das mudanças da estrutura produtiva na educação (VILANOVA, 2011). Além disso, a noção de que o desenvolvimento da ciência e da tecnologia tem como resultado o desenvolvimento social passa a ser questionada, deslocando a posição de neutralidade em que a ciência moderna se encontrava desde a sua fundação. Nessa transição, a questão da educação para a cidadania passa a assumir uma posição de destaque nas discussões sobre os objetivos da educação em ciências, sendo frequentemente mencionada em diretrizes curriculares, orientações didáticas e nos textos que norteiam as políticas públicas em educação.

No entanto, uma ideia difusa sobre cidadania tem sido assumida e mesmo reforçada em diversos textos sobre educação em ciências, o que termina por promover um consenso sobre o tema que é apenas aparente (TOTI et al., 2009). Com o objetivo de contribuir com as discussões acerca das articulações entre educação em ciências e formação para a cidadania são apresentados, neste trabalho, os resultados de uma investigação que teve como objeto de pesquisa livros didáticos de Ciências destinados às séries finais do Ensino Fundamental. Buscamos identificar os diferentes sentidos atribuídos à cidadania nos textos, com base em modelos que dialogam com a filosofia política contemporânea. O trabalho está dividido em três partes: na primeira, apresentamos algumas noções que consideramos importantes para o debate sobre a cidadania no ensino de ciências. Ainda nessa parte buscamos situar esse debate no cenário atual da educação científica, nos termos das tensões colocadas pelas novas demandas educacionais em contraposição a modelos curriculares mais estáveis. A segunda seção apresenta a metodologia da pesquisa e os resultados das análises. Na parte final discutimos os resultados e tecemos algumas considerações a título de conclusões.

\section{OS DISCURSOS DA CIDADANIA E A CIÊNCIA}

O conceito de cidadania está vinculado, essencialmente, aos diferentes modelos de democracia e às concepções de racionalidade construídos ao longo do período moderno. A partir dessa noção, é possível mapear os esforços de se tecer relações entre educação em ciências e educação para a cidadania com base nos modelos normativos de democracia existentes (CALLON, 1999; BARRY, 2000). 
Neste trabalho privilegiamos perspectivas atuais vinculadas ao liberalismo político, por entendermos que essa doutrina norteia os textos que propomos analisar.

Quando nos referimos à educação em ciências, algumas especificidades emergem no contexto das relações com a educação para a cidadania. Nesta seção, apresentamos algumas ideias e propostas de articulação com modelos normativos de democracia ${ }^{1}$ e, ainda, algumas propostas, presentes na literatura, referentes a mudanças curriculares e pedagógicas voltadas para a finalidade do educar para a cidadania no âmbito dessa disciplina (VILANOVA; BANNELL 2011b).

Uma iniciativa de elaboração de modelos que articulam ciência e cidadania pode ser encontrada em Barry (2000). O autor propõe três modelos: (1) consumo da ciência; (2) esfera pública e (3) pesquisa cooperativa.

No modelo do consumo da ciência, as finalidades da disseminação do conhecimento científico estão relacionadas com a escolha da ciência como algo válido para a vida das pessoas. Nesse sentido, o objetivo vai além de ajudar as pessoas a compreender a ciência, reconhecendo que na atual cultura do consumo os indivíduos fazem escolhas mais voltadas ao que lhes é interessante e prazeroso do que de acordo com o que lhes é prescrito (BARRY, 2000). Do ponto de vista normativo, podemos considerar que o modelo de consumo da ciência está vinculado à tradição liberal de cidadania, na qual a sociedade é regulada pelas leis de mercado e os cidadãos são concebidos de forma individualista e instrumental (HABERMAS, 2004). Assim, a prática da cidadania em situações que envolvam a ciência estaria vinculada às vantagens e aos benefícios individuais que ela pode oferecer.

O modelo da esfera pública adota a perspectiva habermasiana de esfera pública e de cidadania. Assim, a ênfase deste modelo está no processo de formação de uma vontade política e de uma opinião pública. Nessa perspectiva, o reconhecimento da ciência como algo importante para a sociedade torna-se suficiente para que os indivíduos sejam engajados no debate sobre as questões científicas. Isso significa que nesse modelo torna-se necessário reconhecer que os cientistas não detêm o monopólio sobre o conhecimento válido, no sentido de que não deveria haver um domínio do debate público por cientistas (BARRY, 2000). Estudos como os de Wynne (1996, apud BARRY, 2000) defendem que os cientistas não possuem o monopólio sobre o conhecimento válido. Os cidadãos cientificamente ativos, nesse sentido, são aqueles engajados criticamente no debate sobre as questões científicas. Com base nesse argumento, Gil-Pérez e Vilches (2005) e DeBoer (2000) também defendem que os conhecimentos dos especialistas não garantem a adoção de decisões adequadas, e que perspectivas mais amplas e variadas são necessárias nas avaliações das repercussões das situações que envolvem ciência e público em médio e em longo prazo. Dessa maneira, os cidadãos podem acrescentar contribuições significativas ao apresentarem perspectivas e interesses mais amplos.

Proposto com base em um estudo desenvolvido por Callon e Rabeharisoa (1999, apud BARRY, 2000), o modelo da pesquisa cooperativa prevê a possibilidade da contribuição de não especialistas na produção do conhecimento científico. Nesse modelo, o que emerge é uma divisão do trabalho complexa e negociada, composta 
por pesquisadores e não especialistas ativos e interessados. Assim, a conduta do cidadão científico ativo envolve um engajamento no processo de pesquisa. Esse modelo também se aproxima do modelo da esfera pública de Habermas, diferindo dele de engajamento. De acordo com Barry (2000), o modelo anterior pressupõe um engajamento crítico, já no caso da pesquisa cooperativa, o conhecimento dos não especialistas é considerado válido na própria construção do conhecimento científico.

De acordo com Praia e Cachapuz (2005), as relações entre a ciência e a técnica, como formas ideológicas de dominação na sociedade, foram desenvolvidas de maneira particularmente interessante por Habermas, cujos modelos também nos auxiliaram na análise dos textos dos livros didáticos que foram objeto desta pesquisa. Habermas (1987) descreve três modelos de articulação: (1) tecnocrático, (2) decisionista e (3) pragmático. Com base nos modelos normativos de democracia, podemos inferir que os dois primeiros estão mais próximos do liberalismo clássico, e o último do modelo habermasiano de esfera pública.

No modelo tecnocrático, os políticos dependem dos especialistas que detêm o poder. A política é determinada, em grande parte, com base em conhecimentos técnico-científicos, na crença de que nos devemos deixar conduzir pela ciência e pela tecnologia, mesmo para resolver questões humanas.

O modelo decisionista é aquele em que a competência dos especialistas não substitui a ação política, mas a coloca ao seu serviço. As escolhas éticas e os meios de concretização dos projetos científicos são separados artificialmente e a escolha dos fins é guiada por valores vivenciados pelos não técnicos. Os meios, no entanto, estão no âmbito de uma racionalidade técnica, ou seja, são guiados por conhecimentos técnico-científicos.

Finalmente, no modelo pragmático a política é negociada entre técnicos e não técnicos, entre políticos e cientistas e entre ambos e a esfera pública. O modelo privilegia o aspecto comunicativo e persegue uma interação real entre os saberes técnicos e os não técnicos. A esfera pública é posicionada em um lugar de obrigação em relação ao saber e à responsabilização. As funções dos cientistas são ampliadas para além da produção de conhecimentos científicos e recomendações técnicas, o que os obriga a refletir sobre as consequências sociais que podem decorrer desses conhecimentos e dessas recomendações e, se necessário, a discutir essas questões com o público.

De acordo com uma abordagem mais específica das relações entre educação em ciências e cidadania - em geral vinculadas à perspectivas do letramento científico - alguns comentaristas defendem a relevância de problematizar os currículos que não relacionam a ciência com assuntos humanos, com a tecnologia e com a vida do cotidiano das pessoas. Schibeci e Lee (2003) indicam que um dos caminhos para se atingir a educação em ciências para a cidadania é viabilizar meios para que a população possa questionar a ciência ao levar em conta decisões pessoais e sociais. Os autores veem na imagem que a população constrói sobre a natureza da ciência e do trabalho do cientista um aspecto nodal para a construção de uma educação em ciências para a cidadania. 
Nessa mesma direção, Praia e Cachapuz (2005) defendem que há cada vez menos sentido em pensar o conhecimento científico fora do contexto da sociedade e do desenvolvimento tecnológico, e que os estudantes de hoje são os cidadãos que necessitarão de elementos de reflexão "sobre acontecimentos que ocorrerão e que terão importância decisiva nos seus percursos de vida, tal como o desenvolvimento da tecnociência, e que hão de revolucionar drasticamente as suas vivências (idem, p. 191)".

Kolstø (2008) defende que no caso da disciplina Ciências, a educação para a cidadania busca preparar os estudantes para uma participação ativa, informada, crítica e responsável em situações nas quais uma visão sobre diferentes aspectos da ciência pode melhorar a qualidade da participação dos estudantes. $\mathrm{O}$ autor afirma que um dos principais argumentos em defesa da educação em ciências para a cidadania é o da democracia, e enfatiza o papel da ciência na sociedade, como por exemplo, nas questões pessoais, sociais e políticas relacionadas a problemas ambientais e de saúde humana. O autor afirma, ainda, que para a maioria das pessoas o contato com a ciência se dá por meio das diversas questões sociocientíficas que elas confrontam como indivíduos e como membros da sociedade e, por essa razão, um currículo ideal de ciências para a cidadania incluiria, entre outras questões, a ênfase na participação democrática, no sentido de fornecer bases psicológicas e morais para esse fim. Além disso, para o autor, a educação em ciências para a cidadania democrática pressupõe conhecimentos relevantes somados a habilidades e atitudes. $\mathrm{O}$ autor defende a relevância da compreensão da natureza da ciência e das interações entre ciência e sociedade para uma argumentação racional sobre questões sociocientíficas.

Nessa perspectiva, a consciência dos aspectos sociais da ciência pode ajudar os cidadãos a se engajarem em questões sociocientíficas, apoiados em uma maior compreensão da legitimidade do debate científico e, ainda, pode ajudá-los a perceber o caráter incerto e o papel da argumentação no trabalho científico. Além disso, a consciência da existência de diferentes modalidades de pesquisa científica e o papel de interesses conflitantes na ciência pós-acadêmica é importante (Kolstø, 2008).

No entanto, os profissionais que atuam nas diferentes esferas da área deparam-se com uma série de problemas de ordem prática ao articular educação em ciências e cidadania. Um deles refere-se à questão da seleção de conteúdos com o objetivo de aumentar a competência dos estudantes em interpretar situações relacionadas com a ciência no cotidiano, quando os conteúdos de caráter humano, (os valores, os limites e as táticas de tomada decisão da ciência) são muito amplos para servir como referência para a sala de aula (Kolstø, 2000). Nesse sentido, torna-se importante especificar quais valores e quais limites enfatizar e, ainda, quais tópicos seriam mais relevantes.

De forma semelhante ao que encontramos na literatura da educação em ciências, as demandas colocadas pela política nacional de avaliação e compra de livros didáticos para as escolas públicas brasileiras (o Programa Nacional do Livro Didático - PNLD) valorizam abordagens vinculadas às interfaces entre ciência e sociedade. Vilanova (2011), ao analisar o PNLD 2008, situa a formação para a 
cidadania como elemento legitimador da mudança discursiva que vem ocorrendo nas esferas acadêmica e na política educacional. No caso mais específico da educação em ciências, as finalidades de formação para a cidadania emergem como justificativa para a introdução da pesquisa na sala de aula, para a introdução da finalidade de compreensão da natureza da ciência, para a substituição dos currículos de ciências e para o desenvolvimento de aptidões para a resolução de problemas que envolvam a ciência. Do ponto de vista epistemológico, as mudanças sugeridas no texto do programa apontam para a substituição de uma percepção de natureza empirista/indutivista por uma concepção pós-positivista. Ainda nas análises de textos do PNLD, a autora destaca um alto grau de comprometimento com as mudanças de cunho epistemológico que vêm sendo defendidas por muitos como possibilidades de aprimoramento das práticas educativas e, em um sentido mais amplo, de democratização da cultura cientifica em contraposição a uma visão autoritária da ciência.

Com base nessas considerações, as análises que desenvolvemos buscam responder de que forma livros didáticos que possuem certa estabilidade no cenário educacional brasileiro incorporam tópicos sobre a educação para a cidadania. A relevância das pesquisas sobre o livro didático não se restringe aos seus aspectos pedagógicos e às suas possíveis influências na aprendizagem e no desempenho dos alunos. O livro didático também é importante por seu aspecto político e cultural, na medida em que reproduz e representa os valores em relação a uma dada visão da ciência, da história, da interpretação dos fatos e do próprio processo de transmissão de conhecimento (LAJOLO, 1996). Nesse sentido, torna-se interessante e relevante compreender como esse instrumento dialoga com as novas demandas colocadas para o ensino de ciências. Na seção seguinte, são apresentados os procedimentos metodológicos e os resultados da pesquisa.

\section{LIVROS DIDÁTICOS DE CIÊNCIAS E CIDADANIA}

\section{Metodologia}

Com o objetivo de garantir que a nossa análise contemple títulos que possuam alguma permanência e estabilidade ao longo do tempo nas classes de ciências das escolas públicas, consideramos a série histórica dos títulos aprovados nas três últimas edições do Programa Nacional do Livro Didático (2005; 2008 e 2011). A partir da edição do PNLD 2005, algumas mudanças na classificação das coleções são implementadas, e por essa razão optamos por observar as coleções avaliadas a partir daquele ano, o que nos fornece uma série de nove anos em termos de utilização.

A partir dos livros selecionados com base na série histórica, utilizamos como segundo critério as escolhas dos professores de Ciências das escolas públicas, de acordo com informação obtida por meio de contato com o Ministério da Educação ${ }^{2}$. 
A partir dos critérios de seleção empregados - as coleções aprovadas nas três últimas edições do programa e as coleções mais escolhidas no PNLD 2008 - definimos as coleções Ciências (Carlos Barros e Wilson Paulino, Editora Ática) e Ciências (Fernando Gewandsznajder, Editora Ática) para para serem analisadas. Nos limites desta investigação, tornou-se necessário reduzir o número de livros analisados. Optamos por privilegiar a análise dos textos contidos nos livros destinados ao sexto e ao oitavo anos do Ensino Fundamental, pois nesse período são abordados componentes curriculares de ambiente e saúde. Consideramos que esses temas são tradicionalmente mais articulados às questões que propomos investigar, uma vez que assuntos de interesse social, como saneamento básico, poluição, doenças sexualmente transmissíveis, entre outros, geralmente são abordados nessas séries do Ensino Fundamental. Assim, esperamos encontrar uma maior frequência de textos que abordam questões relacionadas à cidadania. Apresentamos, a seguir a lista das obras analisadas neste trabalho: Ciências - O Meio Ambiente (Carlos Barros e Wilson Paulino, Ed. Ática, 2008); Ciências - O Corpo Humano (Carlos Barros e Wilson Paulino, Ed. Ática, 2008); Ciências - O Planeta Terra (Fernando Gewandsznajder, Ed. Ática, 2008); Ciências - Nosso Corpo (Fernando Gewandsznajder, Ed. Ática, 2008).

Nas análises que se seguem, trabalharemos a categoria de representação discursiva, conforme proposto pela análise crítica do discurso (ACD) (FAIRCLOUGH, 2001; CHOULIARAKI e FAIRCLOUGH, 1999; FAIRCLOUGH, 2003). Os discursos, segundo Fairclough (2001), configuram formas particulares de construção dos textos, no sentido em que enfatizam determinados conteúdos e áreas do conhecimento de maneira bastante arbitrária. Nesse sentido, os discursos podem ser entendidos como o conjunto de enunciados que articulados por meio da linguagem expressam os valores e os significados das diferentes instituições (MEURER, 2005).

De acordo com a perspectiva da ACD, podemos entender as representações discursivas como recontextualizações ${ }^{3}$. Ao representar um discurso em um texto, os autores o incorporam em um outro contexto, recontextualizando-o. Elementos dos discursos são seletivamente filtrados de acordo com as apropriações em cada contexto, sublinhando as diferenças entre as maneiras pelas quais um tipo particular de discurso é representado em diferentes campos, redes de práticas sociais e gêneros.

A partir dessa perspectiva, essas práticas de seleção podem ser analisadas por meio das categorias de análise da representação discursiva (FAIRCLOUGH, 2003):

(1) Presença: elementos dos discursos que estão presentes/ausentes, proeminentes/com pouco destaque no texto.

(2) Abstração: grau de abstração/generalização do evento concreto.

(3) Organização: como os textos estão organizados.

(4) Adições: o que é adicionado ao discurso representado, por exemplo, explicações/legitimações, avaliações.

No caso desta pesquisa, a análise das representações discursivas possibilita o delineamento dos diferentes discursos sobre cidadania inscritos nos textos pesquisados, além de esclarecer sobre a quais outros discursos eles respondem e, 
ainda, como são construídas interfaces entre a educação em ciências e a educação para a cidadania.

Com o objetivo de analisar a maneira como os textos estão organizados, realizamos um exame dos elementos composicionais dos livros, ou seja, investigamos de que modo eles definem e ordenam a apresentação dos seus conteúdos

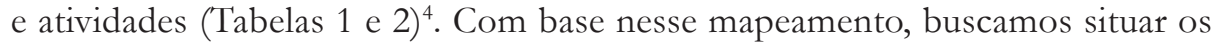
textos que abordavam o tema da cidadania na organização dos livros.

A partir de uma análise exploratória das obras e da identificação dos elementos composicionais e dos enunciados sobre ciência e cidadania, selecionamos os textos que seriam examinados. Essas análises foram realizadas por meio de uma leitura minuciosa dos livros selecionados em que foram identificados os textos que continham enunciados manifestos sobre os discursos da cidadania na educação em ciências, de acordo com o que apresentamos na seção anterior, e a sua localização no texto, de acordo com os elementos composicionais. Foram analisados, ao todo, dezessete segmentos, e alguns exemplos das análises serão apresentados a seguir.

\section{Resultados}

As tabelas a seguir apresentam a distribuição e a frequência dos textos vinculados à formação para a cidadania, de acordo com a localização na estrutura composicional de cada coleção:

Tabela 1: distribuição de textos vinculados ao tema da cidadania no livro "Ciências"

\begin{tabular}{|c|c|c|c|c|}
\hline & $\begin{array}{c}\text { Texto de } \\
\text { abertura }\end{array}$ & $\begin{array}{c}\text { Texto } \\
\text { principal }\end{array}$ & $\begin{array}{c}\text { Atividade } \\
\text { em grupo }\end{array}$ & $\begin{array}{c}\text { Caixa } \\
\text { de texto }\end{array}$ \\
\hline I. 0 meio ambiente & 4 & 1 & 1 & 11 \\
\hline II. 0 corpo humano & 2 & 3 & 4 & 7 \\
\hline
\end{tabular}

Tabela 2: distribuição de textos vinculados ao tema da cidadania no livro "Ciências"

Ciências (Fernando Gewandsznajder)

\begin{tabular}{|c|c|c|c|c|c|}
\hline & $\begin{array}{c}\text { Texto de } \\
\text { abertura }\end{array}$ & $\begin{array}{c}\text { Texto } \\
\text { principal } \\
\text { (conector) }\end{array}$ & $\begin{array}{c}\text { Texto } \\
\text { principal }\end{array}$ & $\begin{array}{c}\text { Atividade } \\
\text { em grupo }\end{array}$ & $\begin{array}{c}\text { Caixa } \\
\text { de texto }\end{array}$ \\
\hline I. 0 planeta Terra & 0 & 5 & 4 & 0 & 4 \\
\hline II. Nosso corpo & 0 & 2 & 5 & 1 & 4 \\
\hline
\end{tabular}

Os livros didáticos analisados nesta pesquisa obedecem a uma organização clássica dos conteúdos da educação em ciências, na qual os conhecimentos são separados de acordo com uma estrutura que acompanha os currículos tradicionais dessa disciplina. Há muitos anos, as tensões existentes entre modelos 
fragmentados de currículo - nas suas interfaces com os livros didáticos - e propostas mais integradoras vêm sendo alvo de uma série de debates, que criticam as bases epistemológicas do modelo tradicional.

De acordo com Macedo e Lopes (2002), no ambiente escolar os princípios de fragmentação do conhecimento se revelam diretamente na forma como a escola é projetada, desenvolvida e usada (sua construção, organização e atribuição de funções), bem como na forma de trabalhar os saberes (disciplinas, planejamentos, atividades, avaliações, etc.). O modelo disciplinar, a despeito de todas as críticas desenvolvidas nos últimos anos, pode ser considerado a ideia pedagógica mais bem sucedida da história do currículo. Tal fato mantém o desenvolvimento do debate curricular com base nas disciplinas. É por meio das disciplinas escolares que os professores se organizam em grupos, orientam sua formação e seu trabalho. É por intermédio da organização disciplinar que o trabalho de professores e alunos nas escolas é controlado: quem pode fazer o quê, quando, em que lugar, de que maneira; qual conteúdo é ministrado em que horário, em que lugar, por quais professores e para quais alunos. Nessa perspectiva, o currículo disciplinar pode ser compreendido como uma tecnologia de organização que controla sujeitos, espaços, tempos e saberes (idem). De acordo com Pretto (1985), os livros didáticos reforçam essa estabilidade, pois possuem influência na elaboração dos programas de ensino, dos modelos de estudo, da formação escolar e na padronização de conteúdos de cada série do Ensino Fundamental.

A análise da localização de abordagens ao tema da cidadania na estrutura composicional dos livros selecionados aponta para uma separação entre os conteúdos tradicionais - contidos no que chamamos de texto principal, e os conteúdos que abordam os conhecimentos, aptidões e valores vinculados às articulações entre ciência e cidadania. É importante observar que de acordo com as Tabelas 1 e 2 , os textos que identificamos como vinculados, por exemplo, a tópicos sobre a natureza da ciência e às relações entre conhecimento científico e participação política estão na sua grande maioria, separados do texto principal. No caso da coleção Ciências (Carlos Barros e Wilson Paulino), a maior ocorrência foi observada nas caixas de texto. A coleção Ciências (Fernando Gewandsznajder), por sua vez, apresentou maior ocorrência de abordagens nos conectores ligados ao texto principal.

Assim, de acordo com nossas análises, podemos sugerir que a negociação das tensões que se colocam entre as demandas impostas pelas recomendações atuais para o ensino de ciências e os recursos ideológicos e materiais mais estáveis da disciplina manifesta-se na organização do texto, na forma de uma separação que permite a coexistência de duas perspectivas sobre ciência e sobre o ensino de ciências nos livros didáticos - a primeira, mais voltada para os conteúdos e valores intrínsecos à prática científica, e a segunda, mais interessada nas articulações entre a ciência e a sociedade.

Com o objetivo de apreender os discursos da cidadania inscritos nesses textos, a seguir apresentamos a segunda parte das análises, na qual buscamos identificar e situar os discursos sobre ciência e cidadania representados nos textos dos livros didáticos analisados. 


\section{Discursos da cidadania nos livros didáticos de ciências}

Como pontuamos anteriormente, nesta seção apresentaremos uma análise dos trechos que identificamos como alinhados aos sentidos de mudança presentes nos debates sobre a educação em ciências. Nessas análises, pudemos identificar uma diversidade de discursos da cidadania que são discutidos a seguir. A apresentação dos dados foi organizada de acordo com os modelos de cidadania citados na primeira seção deste texto, ou seja, não obedece à organização e à sequência dos conteúdos dos livros. Isso facilita ao leitor a apreensão dos sentidos manifestos nos textos, permitindo uma discussão com enfoque nos discursos, que são nosso foco principal nesta seção.

\section{Segmento 1}

\begin{tabular}{|c|l|}
\hline 1 & No município em que você mora, há lixões a céu aberto? \\
\hline & Pesquisar: \\
\hline & - Onde ficam os lixões mais próximos? \\
\hline & - Qual é a situação atual desses depósitos de lixo? \\
\hline 5 & \begin{tabular}{l} 
- Há algum projeto da prefeitura para o tratamento desse local? \\
\hline
\end{tabular} \\
\hline & Que problemas ambientais podem ser causados por lixões a céu aberto? \\
& (Ciências - O meio ambiente: em grupo, p. 78). \\
\hline
\end{tabular}

\section{Segmento 2}

\begin{tabular}{|c|l|}
\hline 1 & A poluição acontece quando o ser humano lança no ambiente certos produtos \\
\hline & químicos que prejudicam a si próprio e a outros seres vivos. Esses produtos \\
\hline & Esses produtos são chamados poluentes. Um carro em movimento, por exemplo \\
\hline 5 & por exemplo, queima gasolina e lança pelo escapamento gases prejudiciais \\
\hline 5 & à saúde. Usar um catalisador diminui o problema, pois é um equipamento \\
& que transforma esses gases em outros menos tóxicos. Você compreende então \\
\hline & por que as indústrias devem usar filtros nas chaminés? E por que deve haver \\
\hline & leis para impedir que elas despejem substâncias tóxicas na água? (Ciências \\
\hline & (Ciências - O Planeta Terra: conector - texto principal, p. 11). \\
\hline
\end{tabular}

\section{Segmento 3}

\begin{tabular}{|c|l|}
\hline 1 & (...) Para reverter o processo de desertificação é preciso que o governo \\
\hline & promova o reflorestamento e a reconstituição da vege- tação natural dessas \\
\hline & regiões, invista em obras de captação de água e dê assistência técnica \\
\hline & aos agricultores, além de melhorar o nivel de educação de toda a população \\
\hline 5 & (Ciências - O PlanetaTerra: de olho no texto, p. 84). \\
\hline
\end{tabular}


Nos segmentos transcritos acima destacamos a presença de enunciados que se vinculam ao modelo denominado por Habermas (1987) como decisionista. Neste modelo, conforme já pontuado, a competência dos especialistas não substitui a ação política, mas a coloca ao seu serviço. Isso é feito no texto por meio de uma série de afirmações das ações que devem ser realizadas nas esferas legislativa e executiva.

O que podemos destacar como ponto comum entre esses enunciados é a afirmação de uma cidadania passiva (ou privada), em que o caráter de participação ativa na vida pública pelos cidadãos está ausente. Conforme pontuado anteriormente, esse modelo ainda é amplamente apoiado, ou seja, no debate sobre a cidadania tende-se a falar mais sobre direitos que sobre responsabilidades. Assim, no caso dos enunciados aqui transcritos, o governo (que é apresentado como uma entidade única, sem considerar suas esferas organizacionais e as respectivas funções) arca com toda a responsabilidade. Para isso, o conhecimento científico disponível deve ser mobilizado pelo "governo" para a solução dos problemas sociais e ambientais, nos marcos de uma racionalidade técnica.

\section{Segmento 4}

\begin{tabular}{|c|l|}
\hline 1 & Dia 2 de março de 2005. A Câmara dos Deputados aprova em Brasília \\
\hline & pesquisas com células-tronco de embriões congelados há pelo menos três anos \\
\hline & em clinicas de fertilização, desde quehaja concordância dos casais doadores. \\
\hline & oram 366 votos a favor, 59 contra e 3 abstenções. A aprovação da lei foi \\
\hline 5 & apreciada como positiva por muitos setores na sociedade. E recebeu \\
\hline & também muitas críticas negativas por parte de outros setores. Na opinião \\
\hline & do grupo, a euforia em relação à aprovação das pesquisas com células-tronco \\
\hline & ejustifica? Eascríticas? (Ciências-Ocorpo humano: em grupo,p.27). \\
\hline
\end{tabular}

\section{Segmento 5}

\begin{tabular}{|c|l|}
\hline 1 & Além de aumentar nosso conbecimento sobre o Universo, o estudo e a \\
\hline & exploração do espaço nos permitem criar novas tecnologias (computadores, \\
\hline & vestimentas resistentes, aprimoramento das telecomunicaçôes, etc.) quepodem \\
\hline 5 & melhorar nossa vida. Mas a exploração espacial pode servir também para \\
\hline 5 & desenvolver armamentos que causam destruição e morte. Trata-se de mais \\
\hline & um exemplo de como a ciência pode ser utilizada para o bem e para o mal \\
\hline & (Ciências - O Planeta Terra: conector - texto principal, p. 200). \\
\hline
\end{tabular}

Nos segmentos de número 4 e 5 identificamos enunciados que se inscrevem no modelo pragmático (HABERMAS, 1987) e da esfera pública (BARRY, 2000). No modelo pragmático, a política é negociada entre técnicos e não técnicos, entre políticos e cientistas e entre ambos e a esfera pública. Nesse modelo, o aspecto 
comunicativo é ressaltado, no sentido de perseguir uma interação real entre os saberes da ciência e outros saberes. De forma semelhante, a ênfase do modelo da esfera pública está no processo de formação de uma vontade política e de uma opinião pública, por meio da ação comunicativa.

Os Segmento 4 apresenta uma questão polêmica - a utilização de embriões humanos para a pesquisa com células-tronco - na interface com a aprovação de uma lei. Por meio da apresentação dessa polêmica, sugere-se o desenvolvimento de uma atividade em grupo na qual os alunos devem examinar as duas posições e debater sobre elas com base nos conhecimentos apreendidos nos conteúdos sobre células-tronco presentes no livro. Assim, a atividade alinha-se com uma das finalidades presentes nas propostas de educação em ciências vinculadas aos modelos citados, a saber, a aptidão de argumentar racionalmente sobre questões sociocientíficas.

No Segmento 5, também de acordo com as finalidades mencionadas, identificamos uma intenção de estímulo a uma atitude crítica frente à produção científica e tecnológica. Embora isso seja apresentado de uma forma polarizada, em termos de "bem" e "mal", o trecho destaca que as descobertas científicas e o desenvolvimento de tecnologias possuem usos diversos, o que abre espaço para uma apreensão crítica do empreendimento científico.

Esses exemplos ilustram a diversidade de concepções de cidadania presentes nos textos que analisamos em nossa pesquisa, que varia no interior de cada coleção. De forma semelhante ao que ressaltamos nas análises da organização dos livros didáticos, os discursos da cidadania manifestos nesses textos alternam entre concepções distintas de educação em ciências no diz respeito à formação do cidadão.

Esses resultados corroboram a noção de que, de uma forma geral, diferentes visões sobre a educação em ciências dividem espaço nos textos da área (ROBERTS, 2007; SANTOS, 2007; SCHULZ, 2009). No entanto, embora as diferentes perspectivas apareçam nos documentos, e possuam pontos complementares, vale ressaltar que em geral as recomendações para a educação científica acabam por priorizar um domínio em relação ao outro, especialmente no que diz respeito à educação formal (SANTOS, 2007). Logo, embora ninguém se posicione exclusivamente a favor de uma ou de outra perspectiva, as propostas de reforma, de uma maneira geral, tendem a enfatizar um ou outro domínio, dependendo da definição de crise e dos interesses dos diferentes grupos sociais (SCHULZ, 2009). Os sentidos da cidadania nos livros didáticos analisados, de forma semelhante, se inscrevem em diferentes discursos, o que ressalta o caráter de tensão permanente entre o modelo estabelecido e as tentativas de mudança, nos marcos de uma luta hegemônica.

\section{CONSIDERACְÕES FINAIS}

Neste trabalho buscamos destacar o caráter da diversidade dos discursos da cidadania científica que dividem espaço nos livros didáticos que analisamos. No que diz respeito aos discursos presentes no texto, destacamos trechos identificados com 
perspectivas mais humanistas (vinculados aos discursos da esfera pública e do pluralismo epistemológico) e cientificistas (vinculados ao discurso decisionista). Os sentidos da cidadania nos livros didáticos analisados se inscrevem em diferentes discursos, o que ressalta o caráter de tensão permanente entre o modelo estabelecido e as tentativas de mudança, em uma disputa por espaço e legitimidade nos livros didáticos para a disciplina.

Buscamos mapear as possibilidades e limitações do processo de mudança na educação em ciências, que entendemos como um trabalho ideológico que busca universalizar os novos sentidos que vêm sendo construídos e que atualmente são atravessados por discursos de formação para a cidadania. Esses sentidos se contrapõem àqueles já estabelecidos nessa área da educação, o que tem como consequência novas hibridizações e algumas contradições que se manifestam no nível do texto.

A distinção das diferentes concepções de cidadania presentes nas propostas de educação em ciências nos parece relevante para uma apreensão crítica das propostas de renovação da educação em ciências que estão presentes, em diferentes níveis, nos textos que norteiam políticas educacionais, nos projetos políticos pedagógicos e nas propostas curriculares. Considerando a tensão existente no interior do próprio campo da educação em ciências - qual seja, a disputa entre as propostas mais conservadoras e as propostas de mudança, nas quais as finalidades de educação para a cidadania se inscrevem - tal apreensão representa uma ferramenta importante para o entendimento das recomendações para o ensino dessa disciplina. Nesse sentido, julgamos relevante a compreensão dos fundamentos político-filosóficos dos textos que subsidiam os caminhos das políticas públicas educacionais, dos currículos e da didática na educação em ciências, em especial na busca pela formação de indivíduos mais comprometidos com a participação nas decisões sobre ciência e seus impactos sobre a sociedade.

\section{NOTAS}

\footnotetext{
${ }^{1}$ Para uma discussão sobre os modelos normativos de democracia vinculados ao liberalismo político, ver Habermas (2004).
}

\footnotetext{
${ }^{2}$ Não tivemos acesso aos dados referentes ao PNLD 2005 e ao PNLD. Por essa razão, no caso desse critério de seleção não foi possível considerar a série histórica das escolhas e, assim, tomamos por base somente as obras mais escolhidas no PNLD 2008.

${ }^{3}$ Ver Bernstein, 1996.

${ }^{4}$ Optamos por não apresentar a contagem geral de cada um dos componentes dos livros didáticos nas tabelas para evitar comparações de frequência que não respondem aos objetivos desta pesquisa.
}

\section{REFERÊNCIAS}

BARRY, A. Making the active science citizenship. 4S/EASST conference, 'Technoscience, citizenship and culture', University of Vienna, 2000.

BERNSTEIN, B. A estruturação do discurso pedagógico: classe, códigos e controle. Petrópolis: Vozes, 1996. 
CALLON, M. The role of lay people in the production and dissemination of scientific Knowledge. Science, Technology and Society, v. 4, n. 1, p. 81-94, 1999.

CHOULIARAKI L. \& FAIRCLOUGH, N. Discourse in late modernity. Edinburgh: Edinburgh University Press, 2001.

DeBOER, G.E. Scientific literacy: Another look at its historical and contemporary meanings and its relationships to science education reform. International Journal of Research in Science Teaching, v.37 n.6, 582-601, 2000.

FAIRCLOUGH, N. Discurso e mudança social. Brasília: Universidade de Brasília, 2000.

FAIRCLOUGH, N. Analysing discourse: textual analysis for social research. London: Routledge, 2003.

GIL-PEREZ, D. \& VILCHES, A. Contribution of science and technological education to citizens' culture. Canadian Journal of Science, Mathematics \& Technology Education, v. 5 n.2, 85-95, 2005.

HABERMAS, J. A inclusão do outro: estudos de teoria política. São Paulo: Loyola, 2004.

KOLSTO, S.D. Science education for democratic citizenship through the use of the history of science. Science \& Education, n.17, 977-997, 2008.

KOLSTO, S.D. Consensus projects: teaching science for citizenship. International Journal of Science Education, v.22 n.6, 645- 664, 2000.

LAJOLO, M. Livro didático: um (quase) manual de usuário. Em Aberto, Brasília, v. 16, n. 69, p. 3-7, 1996.

LOPES, A. C. \& MACEDO, E. Disciplinas e integração curricular: histórias e políticas. Rio de Janeiro: DP\& A, 2002.

PRAIA, J.; CACHAPUZ, A. Ciência-Tecnologia-Sociedade: um compromisso ético. Revista CTS, v.6 n.2, 173-194, 2005.

PRETTO, N. A Ciência nos Livros Didáticos. Salvador: EDUFBA, 1985.

ROBERTS, D.A. Scientific literacy/Science literacy. In S.K. Abell \& N.G. Lederman (Eds.), Handbook of research on science education. Mahwah, NJ: Lawrence Erlbaum Associates, 2007.

Santos, W. L. P. Educação científica na perspectiva de letramento como prática social: funções, princípios e desafios. Revista Brasileira de Educação, v.12 n.36, 2007.

SCHULZ, R.M. Reforming Science Education: Part I. The Search for a Philosophy of Science Education. Science Education, n. 18, 225-249, 2009.

TOTI, F; PIERSON, A.C.; SILVA, L. Diferentes perspectivas de cidadania presentes nas discussões atuais em defesa da abordagem CTS na educação científica. VIII ENCONTRO NACIONAL DE PESQUISA EM EDUCAÇÃO EM CIÊNCIAS, 8.,2009. Florianópolis. Anais... Florianópolis: Universidade Federal de Santa Catarina, 2009.

VILANOVA, R. A Cidadania nos Livros Didáticos de Ciências: mudança discursiva, mediações e tensões na dinâmica de produção das coleções didáticas para a educação pública. 190 p. Tese (Doutorado em Educação) - Pontifícia Universidade Católica do Rio de Janeiro. 2011.

VILANOVA, R. e BANNELL, R. Discursos contemporâneos da cidadania e o ensino de ciências naturais. In: Educação para a cidadania e os limites do liberalismo. Rio de Janeiro: 7 Letras, 2011b.

Data do Recebimento: 06/11/2011

Data de Aprovação: 09/10/2012

Data da Versão Final: 24/10/2012 